Article

\title{
Primary Screening of the Bioactivity of Brackishwater Cyanobacteria: Toxicity of Crude Extracts to Artemia salina Larvae and Paracentrotus lividus Embryos
}

Viviana R. Lopes $^{1,2, *}$, Nuria Fernández ${ }^{3}$, Rosário F. Martins ${ }^{1,4,5}$ and Vitor Vasconcelos ${ }^{1,2}$

1 LEGE/CIIMAR/CIMAR_LA-Laboratory of Ecotoxicology, Genomic and Evolution-Centre of Environmental and Marine Research, University of Porto, Rua dos Bragas 289, 4050-123 Porto, Portugal

2 Department of Biology, Sciences Faculty, University of Porto, Rua do Campo Alegre, 4169-007 Porto, Portugal; E-Mail: vmvascon@fc.up.pt

3 Recursos Mariños e Pesquerías, Facultade de Ciencias, Universidade da Coruña, Alejandro de la Sota, no.1 C.P:15008 A Coruña-España, Spain; E-Mail: nufero@gmail.com (N.F.)

4 Escola Superior de Tecnologia da Saúde do Porto, Instituto Politécnico do Porto, Rua Valente Perfeito 322, 4400-330 Vila Nova de Gaia, Portugal; E-Mail: mrm@estsp.ipp.pt (R.F.M.)

5 IBMC-Institute for Molecular and Cell Biology, University of Porto, R.Campo Alegre 823, 4150-180 Porto, Portugal

* Author to whom correspondence should be addressed; E-Mail: vlopes@ciimar.up.pt; Tel.: 351-223401814; Fax: 351-223390608.

Received: 30 December 2009; in revised form: 18 February 2010 / Accepted: 3 March 2010 / Published: 5 March 2010

Abstract: Cyanobacteria are a diverse group of Gram-negative bacteria that produce an array of secondary compounds with selective bioactivity against vertebrates, invertebrates, plants, microalgae, fungi, bacteria, viruses and cell lines. The aim of this study was to assess the toxic effects of aqueous, methanolic and hexane crude extracts of benthic and picoplanktonic cyanobacteria isolated from estuarine environments, towards the nauplii of the brine shrimp Artemia salina and embryos of the sea urchin Paracentrotus lividus. The A. salina lethality test was used as a frontline screen and then complemented by the more specific sea urchin embryo-larval assay. Eighteen cyanobacterial isolates, belonging to the genera Cyanobium, Leptolyngbya, Microcoleus, Phormidium, Nodularia, Nostoc and Synechocystis, were tested. Aqueous extracts of cyanobacteria strains showed potent toxicity against $A$. salina, whereas in P. lividus, methanolic and aqueous extracts showed embryo toxicity, with clear effects on development during early stages. The results suggest 
that the brackishwater cyanobacteria are producers of bioactive compounds with toxicological effects that may interfere with the dynamics of invertebrate populations.

Keywords: brackishwater cyanobacteria; sea urchin Paracentrotus lividus embryo larval bioassay; brine shrimp Artemia salina lethality test; benthic habitats

\section{Introduction}

Cyanobacteria are an ubiquitous and promising group of prokaryotes from which novel bioactive compounds can be isolated [1]. Cyanobacteria are known for producing a broad array of secondary metabolites, including toxins. Chemically, they can be lipopeptides, amino acids, fatty acids, macrolides and amides with ecological, biological and pharmacological activity [2]. Studies concerning the bioactivity of cyanobacteria have been mainly directed to planktonic forms from marine and freshwater habitats, whilst estuarine originated cyanobacteria are mostly unexplored [1,2].

For cyanotoxin detection and biological activity screening in cyanobacteria, several bioassays have been used. The brine shrimp Artemia salina lethality test is usually used to study the effects of cyanobacteria in coastal environments such as estuarine, marine and hipersaline ecosystems. This bioassay provides a viable tool since $A$. salina is a representative species of the zooplankton community. Moreover, the brine shrimp bioassay is an inexpensive test and without ethical constraints [2-4].

The A. salina bioassay developed by Vanhaecke et al. [5-7] is a useful tool for preliminary biological and pharmacological activity analysis. A. salina is an organism occurring in brackish and marine waters, adaptable to large ranges of salinity $\left(5\right.$ to $\left.250 \mathrm{~g} \mathrm{~L}^{-1}\right)$ and temperature $\left(6\right.$ to $\left.35^{\circ} \mathrm{C}\right)$ [8]. Moreover, this organism is vital to the pelagic ecology of a coastal ecosystem (estuaries, bays, harbors and other nearshore environments). Although it is still considered the basic screening test for cyanobacteria from coastal environments, other sensitive and more specific screening bioassays have been applied, specifically the ones using embryos of invertebrates, viruses and cell lines [8,9]. For studies involving embryogenesis, one of the most described assays uses echinoids, namely sea urchins like Paracentrotus lividus species. This is a common species in European coastal habitats as well as being a vital organism in the benthic ecology of these systems. Furthermore, the sea urchin is an euryhaline organism like the brine shrimp A. salina. Sea urchins are commonly chosen as model organisms since they are known to be very common seashore organisms constituting up to $90 \%$ of the benthic biomass. Furthermore, compared with other employed invertebrates such as arthropods and mollusks, they occupy a key phylogenetic position (deuterostomes). Besides, sea urchins produce a great amount of eggs, feasible to be fertilized in sea water and to develop optically clear embryos among others characteristics, making these organisms good test models. Moreover, the early stages of these organisms are more sensitive to toxicants than the adults and microscopical measures are easy to perform $[6,7,10]$. All these noteworthy characteristics of these two model organisms enable their use in an estuarine study. 
Although the information about cyanobacterial bioactive compounds has been increasing over the last decades, less information of estuarine as well as benthic species is available. The aim of this study was to evaluate the toxic effects of organic and aqueous crude extracts of benthic cyanobacteria isolated from estuaries of North and Centre of Portugal towards the nauplii of the brine shrimp A. salina and embryos of the sea urchin $P$. lividus.

\section{Results and Discussion}

The sampling resulted in the isolation of 18 cyanobacteria isolates from seven different genera, Cyanobium, Leptolyngbya, Microcoleus, Phormidium, Nodularia, Nostoc and Synechocystis of Douro, Minho and Vouga estuaries (Table 1). The isolates were collected from benthic and picoplanktonic habitats with salinity ranging from $5-35 \mathrm{~g} \mathrm{~L}^{-1}$.

Table 1. Cyanobacterial isolates included in the study and their geographic position.

\begin{tabular}{|c|c|c|c|}
\hline \multirow[b]{2}{*}{ Lab code } & \multirow{2}{*}{$\begin{array}{c}\text { Identification } \\
\text { Taxon }\end{array}$} & \multicolumn{2}{|c|}{ Coordinates } \\
\hline & & Latitude & Longitude \\
\hline LEGE 06068 & Cyanobium sp. & $41^{\circ} 8^{\prime} 50.77^{\prime \prime N}$ & $8^{\circ} 39^{\prime} 12.89^{\prime \prime} \mathrm{W}$ \\
\hline LEGE 06069 & Leptolyngbya sp. & $41^{\circ} 8^{\prime} 50.45^{\prime \prime} \mathrm{N}$ & $8^{\circ} 38^{\prime} 2.13^{\prime \prime} \mathrm{W}$ \\
\hline LEGE 06070 & Leptolyngbya sp. & $41^{\circ} 8^{\prime} 50.45^{\prime \prime} \mathrm{N}$ & $8^{\circ} 38^{\prime} 2.13^{\prime \prime} \mathrm{W}$ \\
\hline LEGE 06071 & Nodularia sp. & $40^{\circ} 38^{\prime} 32.87^{\prime \prime} \mathrm{N}$ & $8^{\circ} 39^{\prime} 47.85^{\prime \prime} \mathrm{W}$ \\
\hline LEGE 06072 & Phormidium sp. & $40^{\circ} 40^{\prime} 16.42^{\prime \prime} \mathrm{N}$ & $8^{\circ} 43^{\prime} 24.36^{\prime \prime} \mathrm{W}$ \\
\hline LEGE 06078 & Phormidium sp. & $41^{\circ} 8^{\prime} 12.20^{\prime \prime} \mathrm{N}$ & $8^{\circ} 39^{\prime} 54.65^{\prime \prime} \mathrm{W}$ \\
\hline LEGE 06079 & Synechocystis sp. & $41^{\circ} 8^{\prime} 12.20^{\prime \prime} \mathrm{N}$ & $8^{\circ} 39^{\prime} 54.65^{\prime \prime} \mathrm{W}$ \\
\hline LEGE 07073 & Synechocystis sp. & $40^{\circ} 40^{\prime} 16.42^{\prime \prime} \mathrm{N}$ & $8^{\circ} 43^{\prime} 24.36^{\prime \prime} \mathrm{W}$ \\
\hline LEGE 07074 & Leptolyngbya sp. & $41^{\circ} 8^{\prime} 48.17 " \mathrm{~N}$ & 8॰39'38.79"W \\
\hline LEGE 07075 & Leptolyngbya sp. & $41^{\circ} 8^{\prime} 50.45^{\prime \prime} \mathrm{N}$ & $8^{\circ} 38^{\prime} 2.13^{\prime \prime} \mathrm{W}$ \\
\hline LEGE 07076 & Microcoleus sp. & $41^{\circ} 54^{\prime} 5.00^{\prime \prime} \mathrm{N}$ & $8^{\circ} 48^{\prime} 51.88^{\prime \prime} \mathrm{W}$ \\
\hline LEGE 07077 & Nostoc sp. & $41^{\circ} 52^{\prime} 40.13^{\prime \prime} \mathrm{N}$ & $8^{\circ} 50^{\prime} 6.33^{\prime \prime} \mathrm{W}$ \\
\hline LEGE 07080 & Leptolyngbya sp. & $41^{\circ} 52^{\prime} 2.50^{\prime \prime} \mathrm{N}$ & $8^{\circ} 51^{\prime} 35.90^{\prime \prime} \mathrm{W}$ \\
\hline LEGE 07083 & Synechocystis sp. & $41^{\circ} 8^{\prime} 48.17 " \mathrm{~N}$ & 8॰39'38.79"W \\
\hline LEGE 07084 & Leptolyngbya sp. & $41^{\circ} 52^{\prime} 16.76 " \mathrm{~N}$ & $8^{\circ} 50^{\prime} 39.66^{\prime \prime} \mathrm{W}$ \\
\hline LEGE 07085 & Leptolyngbya sp. & $41^{\circ} 8 ' 50.77 " \mathrm{~N}$ & $8^{\circ} 39^{\prime} 12.89^{\prime \prime} \mathrm{W}$ \\
\hline LEGE 07091 & Leptolyngbya sp. & $40^{\circ} 40^{\prime} 16.42^{\prime \prime} \mathrm{N}$ & $8^{\circ} 43^{\prime} 24.36^{\prime \prime} \mathrm{W}$ \\
\hline LEGE 07092 & Microcoleus sp. & $40^{\circ} 40^{\prime} 16.42^{\prime \prime} \mathrm{N}$ & $8^{\circ} 43^{\prime} 24.36^{\prime \prime} \mathrm{W}$ \\
\hline
\end{tabular}

The putative bioactivity of these cyanobacteria was evaluated against $A$. salina and the sea urchin $P$. lividus. In the A. salina lethality bioassay, the aqueous crude extracts of strains LEGE 07075, LEGE 07076, LEGE 06070 and LEGE 07074 were the most toxic. The $\mathrm{LC}_{50}$ values obtained for LEGE 07075, LEGE 07076 and LEGE 07074 were $8.95,12.10$ and $13.78 \mathrm{mg} \mathrm{mL}^{-1}$, respectively. The other extracts had $\mathrm{LC}_{50}$ values above $15 \mathrm{mg} \mathrm{mL}^{-1}$ (Table 2). The results suggest that the aqueous crude extracts are more toxic than the organic ones (hexane and methanolic). Indeed, none of the hexane extracts induced mortality above 7\%, which was also observed for some methanolic extracts (data not shown). Even still, one of 18 methanolic extracts, LEGE 06071, induced acute effects on the A. salina 
nauplii with a $\mathrm{LC}_{50}$ of $17.81 \mathrm{mg} \mathrm{mL}^{-1}$ (95\% confidence interval of 11.63 to $27.30 \mathrm{mg} \mathrm{mL}^{-1}$ ). It was also observed that the $\mathrm{LC}_{50}$ values calculated were more prominent at $48 \mathrm{~h}$, which confirms the sensitivity of nauplii observed in previous works [3,8], suggesting that toxicity is much higher after $48 \mathrm{~h}$ exposure than after $24 \mathrm{~h}$. Moreover, previous work showed that the crude extracts of marine Synechocystis strains reduced the survival of A. salina nauplii similarly to the results obtained here [11]. The most toxic extracts in this work were those of the filamentous forms Leptolyngbya and Microcoleus. These results may suggest that those genera are candidates for the production of a broad range of bioactive compounds in estuarine environments. A wide array of cyanobacterial bioactive metabolites is produced by large nonribosomal peptide enzymes, specifically synthetases and polyketide synthetases. From previous studies, it is known that the nonribosomal peptide enzyme genes are more abundant among the filamentous and heterocystous cyanobacteria $[12,13]$.

Table 2. 24-h and 48-h LC $\mathrm{LC}_{50}$ values (with 95\% confidence limits) for A. salina exposed to 18 estuarine cyanobacterial methanolic and aqueous extracts.

\begin{tabular}{|c|c|c|c|c|c|c|c|}
\hline \multirow{4}{*}{$\begin{array}{l}\text { Code } \\
\text { LEGE } 06068\end{array}$} & \multicolumn{7}{|c|}{$\mathrm{LC}_{50}(95 \%$ confidence limits $) \mathrm{mg} \mathrm{mL}^{-1}$} \\
\hline & \multicolumn{3}{|c|}{ Methanolic extracts } & \multicolumn{4}{|c|}{ Aqueous extracts } \\
\hline & $24 \mathrm{~h}$ & \multicolumn{2}{|c|}{$48 \mathrm{~h}$} & \multicolumn{2}{|r|}{$24 \mathrm{~h}$} & \multicolumn{2}{|c|}{$48 \mathrm{~h}$} \\
\hline & - & - & - & - & - & 79.92 & $(36.28-653.08)$ \\
\hline LEGE 06069 & - & - & - & - & - & 32.62 & $(27.22-39.10)$ \\
\hline LEGE 06070 & - & - & - & - & - & 15.42 & $(5.00-27.56)$ \\
\hline LEGE 06071 & - & 17.81 & $(11.63-27.30)$ & - & - & 53.20 & $(37.97-65.94)$ \\
\hline LEGE 06072 & - & - & - & - & - & 20.13 & $(12.18-30.36)$ \\
\hline LEGE 06077 & - & - & - & 72.11 & $(54.96-94.60)$ & 72.01 & $(57.88-86.61)$ \\
\hline LEGE 06078 & - & - & - & - & - & 28.60 & $(8.93-40.58)$ \\
\hline LEGE 06079 & - & - & - & 22.63 & NR & - & - \\
\hline LEGE 07073 & - & - & - & - & - & - & - \\
\hline LEGE 07074 & - & - & - & - & - & 13.78 & $(11.46-16.55)$ \\
\hline LEGE 07075 & - & - & - & - & - & 8.95 & $(4.98-15.00)$ \\
\hline LEGE 07076 & - & - & - & - & - & 12.10 & $(9.95-14.64)$ \\
\hline LEGE 07080 & - & - & - & - & - & - & - \\
\hline LEGE 07083 & - & - & - & - & - & - & - \\
\hline LEGE 07084 & - & - & - & 32.62 & $(28.00-38.00)$ & 32.62 & $(28.00-38.00)$ \\
\hline LEGE 07085 & - & - & - & 94.9 & $(73.14-133.15)$ & 64.61 & $(52.23-79.92)$ \\
\hline LEGE 07091 & - & - & - & 26.15 & $(19.85-34.4)$ & 26.15 & $(19.85-34.4)$ \\
\hline LEGE 07092 & - & - & - & 20.68 & $(15.17-28.18)$ & 18.08 & (14.15-23.10) \\
\hline
\end{tabular}

In the P. lividus bioassay, teratogenic effects at the pluteus larva stage and development inhibition effects at early stages, were observed. When the fertilized sea urchin eggs were exposed to aqueous and 70\% methanolic crude cyanobacterial extracts, morphological abnormalities were observed: specifically, delayed or arrested development in the different early embryonic stages, loss of cell aggregation, larval malformations (four arms not formed or short length) and decreased the larval growth (Figure 1). 
Figure 1. Effects of estuarine cyanobacterial extracts on embryonic development of sea urchin P. lividus after $48 \mathrm{~h}$ of exposure (a) Normal pluteus larva from the control treatment.

(b) Abnormal four arms larva (with equal sized arms and shorter larval length).

(c) Abnormal larva with only one-arm developed after exposure to cyanobacterial extracts.

The bar represents $100 \mu \mathrm{m}$.

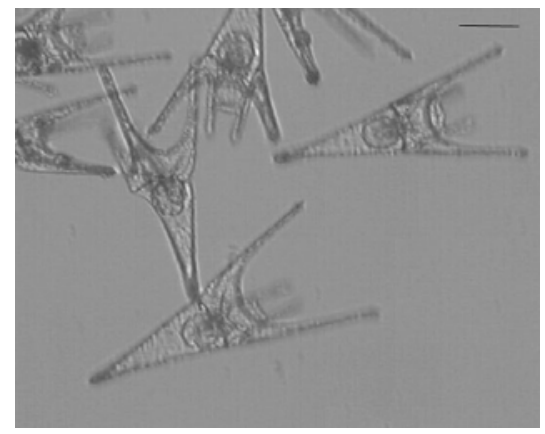

(a)

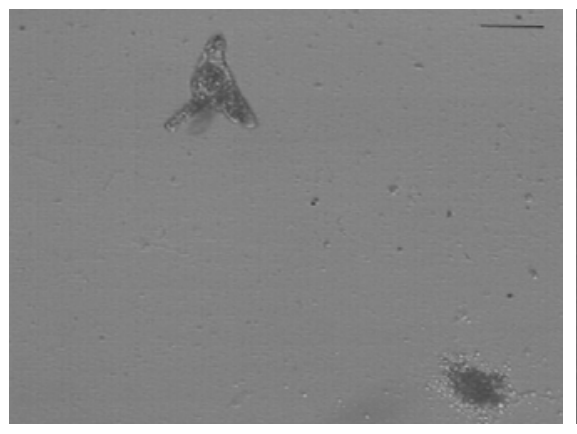

(b)

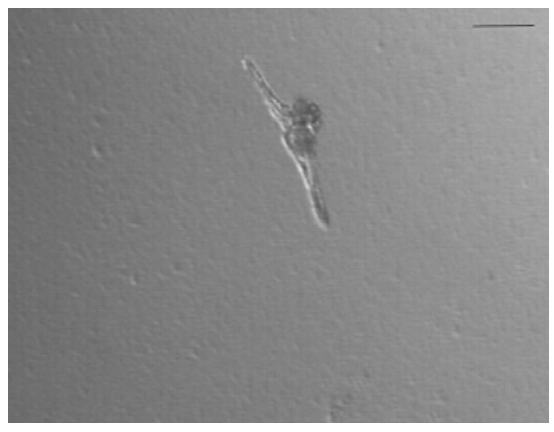

(c)

The results of the $P$. lividus embryo-larval toxicity bioassay after $48 \mathrm{~h}$ of incubation with cyanobacterial extracts revealed that in the control trial $96.7 \pm 7.2 \%$ of the $P$. lividus fertilized eggs developed to normal pluteus larva with an average length of $471.46 \pm 6.20 \mu \mathrm{m}$. Increasing the concentration of the extract from 1.56 to $25.0 \mathrm{mg} \mathrm{mL}^{-1}$ did not produce lethal effects for either extract, although we observed developmental arrest at early stages at $1.56 \mathrm{mg} \mathrm{mL}^{-1}$ up to the concentration of $25.0 \mathrm{mg} \mathrm{mL}^{-1}$ (Table 3$)$. At the highest concentration of the aqueous extracts $\left(25.0 \mathrm{mg} \mathrm{mL}^{-1}\right)$, embryos reached the morula, blastula or gastrula stages. Nevertheless, the LEGE 06069, LEGE 06077 and LEGE 07091 extracts led to slower embryo-larval development with the morula the only stage observed for the series of concentrations. The same observations were made with the $70 \%$ methanolic extracts LEGE 06070 and 07074 . For the $70 \%$ methanolic extracts, at the highest concentration, $72 \%$ induced delayed embryo development to the morula stage in contrast to only $33 \%$ of the aqueous extracts. These results may indicate that $70 \%$ methanolic extracts can induce more toxic effects than the aqueous ones.

Furthermore, an extract concentration dependent increase of toxic effects in P. lividus pluteus larva could be observed. Exceptions were LEGE 06069 and LEGE 07091 aqueous and LEGE 06079 methanolic extracts, which only led to the development of the morula stage independently of the extract concentration. Above $6.25 \mathrm{mg} \mathrm{mL}^{-1}$, for both aqueous and methanolic extracts, few sea urchin embryos could develop to pluteus stage. The embryos obtained from zygotes exposed to concentrations below $6.25 \mathrm{mg} \mathrm{mL}^{-1}$ of the aqueous extracts mainly developed 4 four-arm pluteus larva with significant differences in larval length compared with the control $(p<0.05)$. For the LEGE 06079, LEGE 06071, LEGE 07080, LEGE 07084, LEGE 07074 and LEGE 07075 aqueous extracts, despite the larvae having normal development with four-arms, in all cases ANOVA showed that the larval lengths were significantly shorter $(\mathrm{p}<0.05)$ than those of the control trial (Figure $2 \mathrm{~A}$ and $\mathrm{B}$ ). 
Table 3. Embryonic development of $P$. lividus after $48 \mathrm{~h}$ exposure to different concentrations (25.0 to $1.56 \mathrm{mg} \mathrm{mL}^{-1}$ ) of aqueous and methanolic crude extracts of estuarine cyanobacterial isolates.

\begin{tabular}{ccccccccccc}
\hline \multicolumn{1}{c}{ Cqueous } & 25.00 & 12.50 & $\mathbf{6 . 2 5}$ & $\mathbf{3 . 1 2}$ & $\mathbf{1 . 5 6}$ & $\mathbf{2 5 . 0 0}$ & $\mathbf{1 2 . 5 0}$ & $\mathbf{6 . 2 5}$ & $\mathbf{3 . 1 2}$ & $\mathbf{1 . 5 6}$ \\
\hline LEGE 06068 & G & G & G & P & P & M & M & M/G & M/P & G/P \\
LEGE 06069 & M & M & M & M & M & M & M & P/L & G & M/P/L \\
LEGE 06070 & B & B & B & G/P & G/P/L & M & M & M & M/G & M/G/L \\
LEGE 06078 & B & B & B & B & G/P & G & G/P & G/P & G/P & G/P \\
LEGE 06079 & M & G & P & L & L & M & M & M & M & M/L \\
LEGE 06071 & G & P & L & L & L & B & B & B & B & B \\
LEGE 06072 & G & G & G/P & G/P & P & M & M/B & G & G & P \\
LEGE 07080 & M & M & M & M/G/L & M/G/L & B & G & G/P & L & L \\
LEGE 07084 & B & B & B & B & G/P/L & G & G & P/L & L & L \\
LEGE 07074 & B & B & B & G & G/P/L & M & M & M & P/L & M/G/L \\
LEGE 07085 & B & B & B & B & G & B & B & G & P & P \\
LEGE 07075 & G & G & G & P & L & M & B & P & G & P/L \\
LEGE 07091 & M & M & M & M & M & M & M & G & P/L & L \\
LEGE 07076 & B & B & B/G & B/G & G & M & M & M & G & M/G/L \\
LEGE 07092 & G & G & G & G & G & M & M & M/G & G/P & G/L \\
LEGE 06077 & M & M & M & M & G/P & M & M & M/P & P & P/L \\
LEGE 07073 & B & B & B & G & G & M & M & M & P & M/P/L \\
LEGE 07083 & M & G/P & P/L & L & L & M & B & B & B/G/P & L \\
\hline
\end{tabular}

M-morula, B-blastula, G-gastrula, P-prism and L-pluteus larva.

Figure 2. Mean values of length of normal P.lividus larvae $( \pm \mathrm{SE})$ incubated on aqueous cyanobacterial extracts (A) and methanolic extracts (B), and on sea water as control. Asterisks indicate significant differences $(* * \mathrm{P} \leq 0.05)$ between extract and control.

A

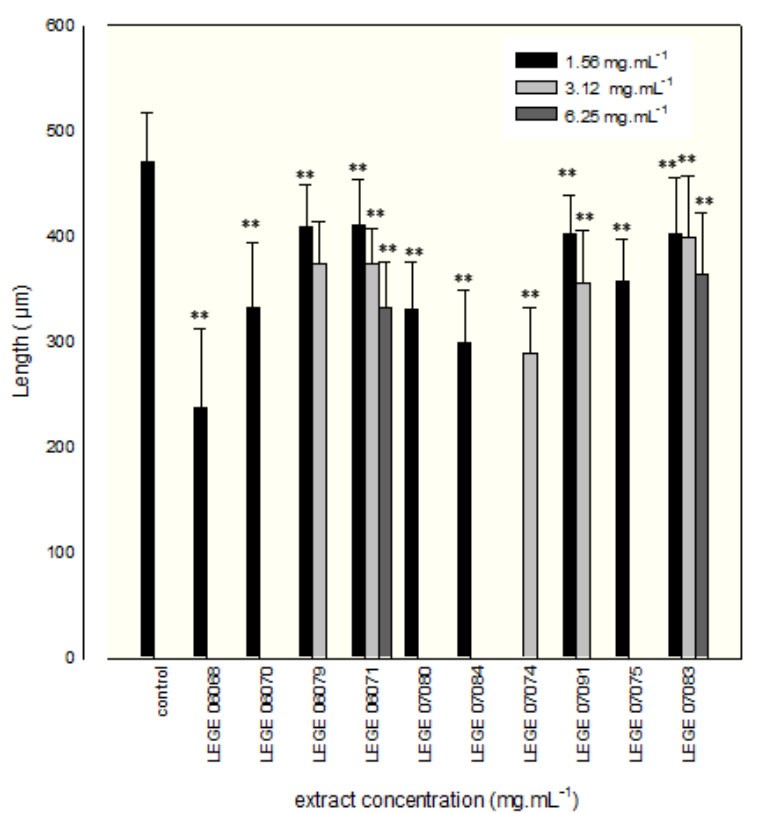

B

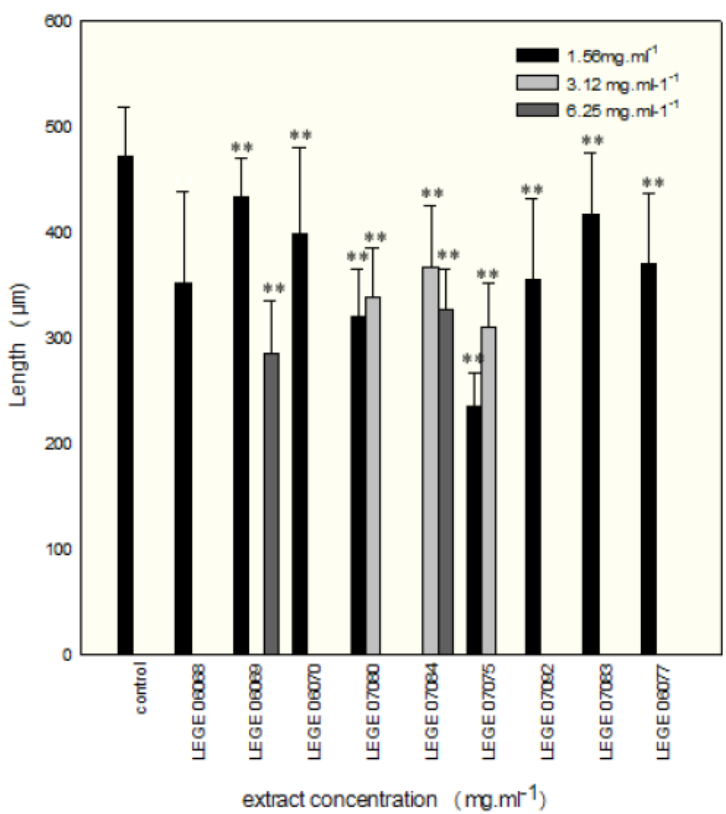


Figure 3. Comparison of the mean values of length of normally developed $P$. lividus larvae $( \pm \mathrm{SE})$ incubated on cyanobacterial methanolic extracts and on sea water control to a concentration of $1.6 \mathrm{mg} \mathrm{mL}^{-1}$. Asterisks indicate significant differences $(* * \mathrm{P} \leq 0.05)$ between extract and control.

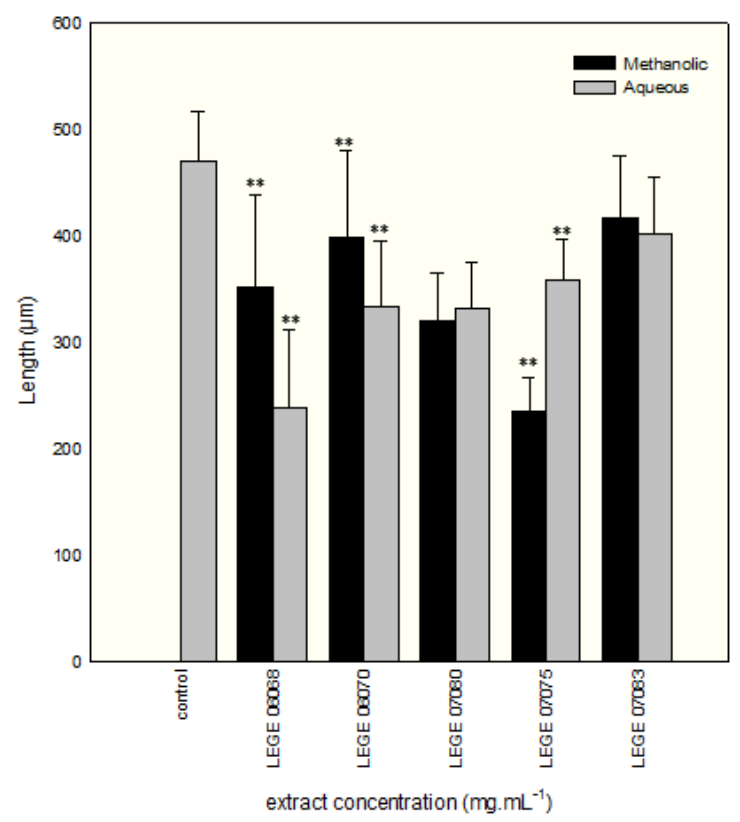

For all the extracts and concentrations, significant differences were found $(\mathrm{p}<0.05)$ from the control, excluding the pairs with concentrations of $1.6-3.2 \mathrm{mg} \mathrm{mL}^{-1}$ and $3.2-6.3 \mathrm{mg} \mathrm{mL}^{-1}$ of LEGE 07083 aqueous extract ( $p=0.354$ and 0.787 , respectively). The results are in agreement with the results of Martins et al. [11] that also observed anomalies at the larval stage and inhibition of the embryogenesis exposed to marine cyanobacterial extracts, although the isolates now studied are from estuarine habitats. Our data demonstrate the presence of compounds in the extracts that can interfere with growth factors, as observed in previous studies [15]. Furthermore, we can also infer that estuarine cyanobacterial extracts have other compounds that probably inhibit the DNA synthesis and effect skeleton formation, since loss of cell aggregation was observed at morula stage as well as the inhibition of larval morphogenesis.

As already demonstrated for freshwater and marine cyanobacteria [16,17], the results obtained highlight the notion that cyanobacteria from estuarine habitats, specifically benthic forms, can be a prolific source for new bioactive compounds.

\section{Experimental Section}

\subsection{Cyanobacteria sampling}

Eighteen cyanobacterial strains were isolated from Portuguese Atlantic estuaries, specifically, Minho, Douro and Vouga, located for $42^{\circ} 15^{\prime}$ to $40^{\circ} 15^{\prime}$ north latitude and $8^{\circ} 54^{\prime}$ to $8^{\circ} 38^{\prime}$ west longitude (Figure 4). The samples were collected during the low tidal from benthos environments and water samples. Isolation and culture were performed in Z8 liquid medium [18] supplemented with 
$\mathrm{NaCl}$ (10 to $35 \mathrm{mg} \mathrm{mL}^{-1}$ ). Isolation procedure was done with use of the micromanipulation technique of single cells using both liquid and solid medium [19]. Cultures were grown under laboratory conditions at $25{ }^{\circ} \mathrm{C}$, light intensity of $20.8-27.4 \times 10^{-6} \mathrm{E} \mathrm{m}^{-2} \mathrm{~s}^{-1}$ and a light/dark cycle of 14/10 $\mathrm{h}$. Cultures examined were unicyanobacterial and non-axenic.

Figure 4. Geographic position of the sampling sites-Star symbols point out the sites: M-Minho estuary; D-Douro estuary and V-Vouga estuary.

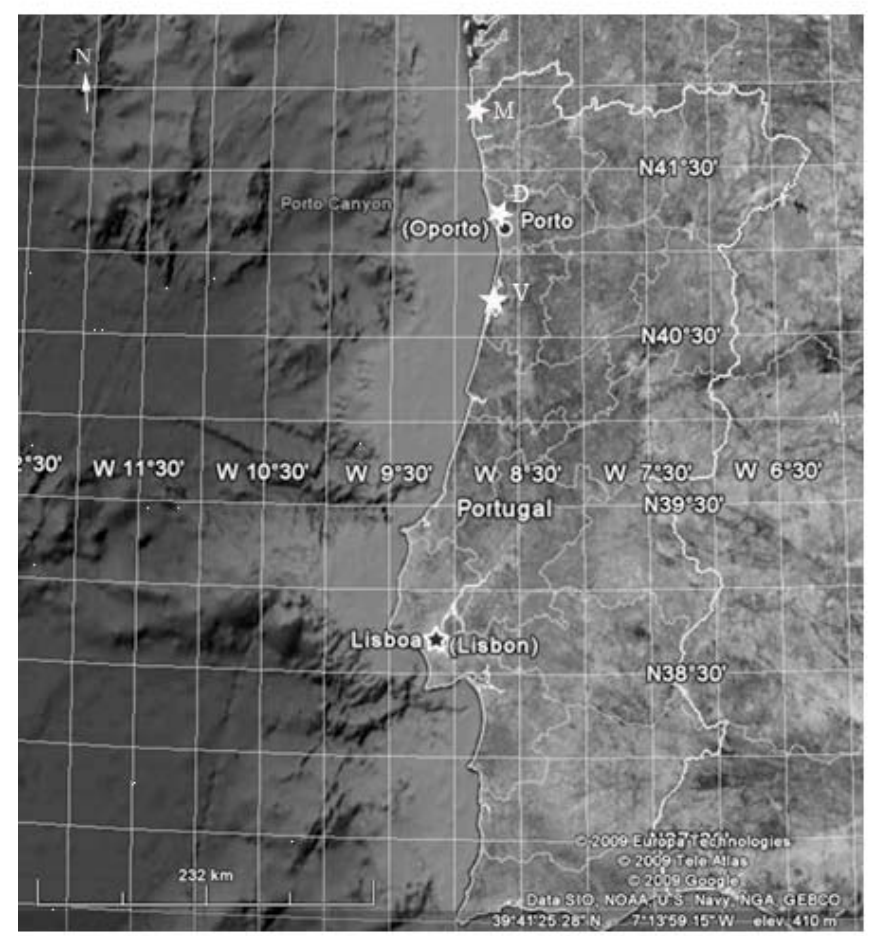

\subsection{Taxonomic characterization}

Cyanobacterial strains were identified based on a morphological and molecular approach at the genus level. In regard to morphology, cells were analyzed by light microscopy and characterized according to Komárek and Anagnostidis [20,21] and Boone and Castenholz [22]. The molecular identification was based on 16S rRNA gene sequencing using primers and protocol previously described $[23,24]$.

\subsection{Preparation of extracts}

For the preparation of the extracts, 6 to 8-week-old cultures were harvested by centrifugation, frozen, freeze-dried and stored at $-20{ }^{\circ} \mathrm{C}$. Freeze-dried cyanobacterial material was extracted three times for 20 seconds in ice with hexane (P.A. Sigma, USA), methanol (P.A. Sigma, USA), and distilled water for the A. salina bioassay, and with methanol $70 \%(\mathrm{v} / \mathrm{v})$ and distilled water for sea urchin embryo-larval bioassay maintaining 1 hour in ice between each cycle of extraction. The supernatants collected by centrifugation (9300 $\mathrm{g}$ for 10 minutes) were evaporated and dissolved in artificial sea water $(\mathrm{pH} 8.0 \pm 0.01)$. A 2-fold series of dilutions of each extract were made from an 
initial concentration of 100 and $25 \mathrm{mg}$ dry weight. $\mathrm{mL}^{-1}$ to test with A. salina and P. lividus, respectively.

\subsection{Preparation of the bioassays}

The A. salina nauplii and the P.lividus embryo-larval bioassays were conducted in 96-well and 24-well microplates, respectively. Three replicates were performed for each treatment and control. Two negative controls were used, one only with artificial sea water and the other with the solvents used in the extractions. Solvents were evaporated and the residue dissolved in artificial seawater (ASW).

\subsection{A. salina lethality assay}

Dried cysts (JBL Novotemia, Germany) of A. salina were hatched in artificial sea water $\left(1 \mathrm{~g}\right.$ cyst $\left.\mathrm{L}^{-1}\right)$ at $25^{\circ} \mathrm{C}$ under continuous illumination and aeration. After $24 \mathrm{~h}$ of incubation, the $A$. salina nauplii were collected and 10-20 individuals were transferred to each well. The assay consisted of the exposure of A. salina nauplii to a 2 -fold series of dilutions of each extract. The toxicity was determined after 24 and $48 \mathrm{~h}$ of exposure at $25^{\circ} \mathrm{C}$ in darkness. The number of dead larvae in each well was counted, as well as the total number of brine shrimps after Lugol's fixation. Larvae were considered dead if no internal or external movement was observed during 30 seconds. Results are presented as percentage of mortality and $\mathrm{LC}_{50}$ values.

\subsection{P. lividus embryo-larval toxicity assay}

The embryo-larval bioassay was assessed by using embryos of the Mediterranean sea urchin $P$. lividus. Sea urchins were collected from wild populations on rocky shores at Valadares beach $\left(41^{\circ} 05^{\prime} 30.37^{\prime \prime} \mathrm{N} ; 8^{\circ} 39^{\prime} 28.40^{\prime \prime} \mathrm{W}\right)$. Adult $P$. lividus specimens were dissected and the gametes collected directly from the gonads [19]. In vitro fertilization was induced in ASW. Successful fertilization rate was determined by counting the fertilized eggs in $10 \mu \mathrm{L}$ aliquots. This assay consisted of exposing $P$. lividus fertilized eggs to $3 \mathrm{~mL}$ of a series of dilutions of aqueous and $70 \%$ methanolic crude filtered cyanobacterial extracts $\left(0.2 \mu \mathrm{m}\right.$ pore filter) and to controls (ASW) during $48 \mathrm{~h}$ at $20^{\circ} \mathrm{C}$. The maximum concentration used of each extract was $25 \mathrm{mg}$ dry weight $\mathrm{mL}^{-1}$. In each well, 20 fertilized eggs per $\mathrm{mL}$ of solution were added. After $40 \%$ formalin fixation, the embryogenesis success was evaluated by measuring the pluteus larval percentage and length.

\subsection{Statistical analyses}

The data obtained from the A. salina bioassay were analyzed with the Probit analysis or (Trim) Spearman-Kaber depending on the number of partial mortalities. The endpoint determined was the $\mathrm{LC}_{50}$ values with $95 \%$ confidence intervals at 24 and $48 \mathrm{~h}$. The results of sea urchin embryo-larval toxicity test are reported as the mean larval length \pm standard deviation (SD). The goodness of fit of the data to normal distribution was test applying the Kolmogorov-Smirnov statistic. The statistical 
significance of the different means observed in the control and those in the extracts were determined by one-way analysis of variance (ANOVA). The statistical analysis was performed with SPSS software (version 17.0, USA) after the underlying assumptions of normality and homoscedasticity were checked. When those assumptions were not met, a non-parametric Kolmogorov-Smirnov test for two- independent samples was applied. A significant level of $p<0.05$ was accepted.

\section{Conclusions}

In this study, 18 crude extracts of estuarine cyanobacteria isolates were assessed for toxic effects against the A. salina nauplii and the P. lividus sea urchin embryos. Among the cyanobacterial isolates, $78 \%$ are filamentous forms and the other $20 \%$ coccoid, with Leptolyngbya being the most dominant genus. Furthermore, the strains belonging to the genus Leptolyngbya were collected only from benthic environments, which underline that the benthic forms can be a good source of novel compounds, and also a putative risk to the benthic community.

The results show that aqueous crude extracts can induce more ecotoxicological effects on $\mathrm{A}$. salina nauplii than the methanolic and lesser than hexane extracts. Regarding the sea urchin bioassay, the data obtained indicate teratogenic effects at the pluteus larva stage and toxic effects during early embryogenesis of $P$. lividus induced by the methanolic and aqueous crude extracts.

The data obtained may also suggest that estuarine cyanobacteria are producers of bioactive compounds of hydrophilic and hydrophobic nature. The presence of hydrophilic compounds in the extracts can pose a putative ecological threat to these environments, since these compounds become more available after cell lysis or when released to the environment. Still, the putative different nature of the compounds can be seen also as potential source of new pharmacological compounds.

The outcome of this work allowed us to reinforce the notion that is important to increase the research on estuarine cyanobacteria, with further characterization of their bioactive compounds.

\section{Acknowledgements}

This study was supported by SFRH/BD/32486/2006 grant of Portuguese Governmental Foundation for Science and Technology (FCT). We would like to thank you for the help given in brine shrimp bioassay by the student of fellowship "Integration into Research Grants”, Claúdia Silva.

\section{References and Notes}

1. Singh, S.; Kate, B.N.; Banerjee, U.C. Bioactive compounds from cyanobacteria and microalgae: an overview. Crit. Rev. Biotechnol. 2005, 25, 73-95.

2. Jaiswal, P.; Singh, P.K.; Prasanna, R. Cyanobacterial bioactive molecules--an overview of their toxic properties. Can. J. Microbiol. 2008, 54, 701-717.

3. Sánches-Fortún, S.; Sanz, S.; Barahona, M.V. Acute toxicity of several organophosphorous insecticides and protection by cholinergic antagonist and 2-PAM on Artemia salina larvae. Arch. Environ. Contam. Toxicol. 1996, 31, 391-398. 
4. Caldwell, G.S.; Bentley, M.G.; Olive, P.J.W. The use of a brine shrimp (Artemia salina) bioassay to assess the toxicity of diatom extracts and short chain aldehydes. Toxicon 2003, 42, 301-306.

5. Vanhaecke, P.; Persoone, G.; Claus, C.; Sorgeloos, P. Proposal for a short-term toxicity test with Artemia nauplii. Ecotoxicol. Environ. Saf. 1981, 5, 382-387.

6. Sleet, R.B.; Brendel, K. Brine shrimp, Artemia salina: a potential screening organism for initial teratology screening. Proc. West Pharmacol. Soc. 1983, 26, 169-170.

7. Carballo, J.L.; Hernandez-Inda, Z.L.; Perez, P.; Garcia-Gravalos, M.D. A comparison between two brine shrimp assays to detect in vitro cytotoxicity in marine natural products. BMC Biotechnol. 2002, 2, 17.

8. Nunes, B.S.; Carvalho, F.D.; Guilhermino, L.M.; Van Stappen, G. Use of the genus Artemia in ecotoxicity testing. Environ. Pollut. 2006, 14, 453-462.

9. Krueger, R.J. Book Review of Bioactive Natural Products. Detection, Isolation, and Structural Determination. Second Edition. J. Med. Chem. 2008, 51, 3659-3659.

10. Boudouresque, C.F.; Verlaque, M. Ecology of Paracentrotus lividus. In: Edible Sea Urchins: Biology and Ecology; Lawrence, J.M., Ed.; Elsevier publ.: Amsterdam, The Netherlands, 2007; pp. 243-285.

11. Martins, R.; Fernandez, N.; Beiras, R.; Vasconcelos, V. Toxicity assessment of crude and partially purified extracts of marine Synechocystis and Synechococcus cyanobacterial strains in marine invertebrates. Toxicon 2007, 50, 791-799.

12. Ehrenreich, I.M.; Waterbury, J.B.; Webb, E.A. Distribution and diversity of natural product genes in marine and freshwater cyanobacterial cultures and genomes. Appl. Environ. Microbiol. 2005, 71, 7401-7413.

13. Alexandra, A.R.; Janine, N.C.; Mohamed, A.M.; Brett, A.N. The Synechocystis sp. PCC6803 SfpType Phosphopantetheinyl Transferase Does Not Possess Characteristic Broad-Range Activity. ChemBioChem 2009, 10, 1869-1877.

14. Sugni, M.; Mozzi, D.; Barbaglio, A.; Bonasoro, F.; Candia Carnevali, M.D. Endocrine disrupting compounds and echinoderms: New ecotoxicological sentinels for the marine ecosystem. Ecotoxicology 2007, 16, 95-108.

15. Da Rocha, A.B.; Lopes, R.; Schwartsmann, G. Natural products in anticancer therapy. Curr. Opin. Pharmacol. 2001, 364-369.

16. Wiegand, C.; Pflugmacher, S. Ecotoxicological effects of selected cyanobacterial secondary metabolites: A short review. Toxicol. Appl. Pharmacol. 2005, 203, 201-218.

17. Mundt, S.; Kreitlow, S.; Nowotny, A.; Effmert, U. Biochemical and pharmacological investigations of selected cyanobacteria. Int. J. Hyg. Environ. Health 2001, 203, 327-334.

18. Kotai, J. Instructions for Preparation of Modified Nutrient Solution Z8 for Algae; Norwegian Institute for Water Research: Blindern, Oslo, Norway, 1972; p. 5.

19. Ripka, R. Isolation and purification of cyanobacteria. Methods Enzymol. 1988, 167, 3-28.

20. Komárek, J.; Anagnostidis, K. Cyanoprokaryota, Part 1: Chroococcales, Süsswasserflora von Mitteleuropa, Bd 19/1; Gustav Fischer Verlag: Stuttgart, Germany, 1998; p. 548.

21. Komárek, J.; Anagnostidis, K. Cyanoprokaryota, Part 2: Oscillatoriales, Süsswasserflora von Mitteleuropa, Bd19/2; Elsevier/Spektrum Akademischer Verlag: Heidelberg, Germany, 2005; p. 759. 
22. Boone, D.R.; Castenholz, R.W. Bergey's Manual of Systematic Bacteriology; Garrity, G.M., Ed.; Springer-Verlag: New York, NY, USA, 2001; Vol. 1, p. 600.

23. Jungblut, A.-D.; Neilan, B.A. Molecular identification and evolution of the cyclic peptide hepatotoxins, microcystin and nodularin, synthetase genes in three orders of cyanobacteria. Arch. Microbiol. 2006, 185, 107-114.

24. Neilan, B.A.; Jacobs, D.; Del Dot, T.; Blackall, L.L.; Hawkins, P.R.; Cox, P.T.; Goodman, A.E. rRNA sequences and evolutionary relationships among toxic and nontoxic cyanobacteria of the genus Microcystis. Int. J. Syst. Bacteriol. 1997, 47, 693-697.

25. Fernández, N.; Beiras, R. Combined toxicity of dissolved mercury with copper, lead and cadmium on embryogenesis and early larval growth of the Paracentrotus lividus sea-urchin. Ecotoxicology 2001, 10, 263-271.

Samples Availability: Available from the authors.

(C) 2010 by the authors; licensee Molecular Diversity Preservation International, Basel, Switzerland. This article is an open-access article distributed under the terms and conditions of the Creative Commons Attribution license (http://creativecommons.org/licenses/by/3.0/). 